DOI: https://doi.org/10.24127/ajpm.v10i2.3605

\title{
PEMODELAN POT TANAMAN SUKULEN MELALUI PENGGABUNGAN BENDA GEOMETRI BIDANG DAN KURVA BEZIER
}

\author{
Dzurotul Mutimmah $^{1^{*}}$, Novi Prayekti ${ }^{2}$ \\ ${ }^{1,2}$ Universitas PGRI Banyuwangi, Banyuwangi, Indonesia \\ *Corresponding author \\ E-mail: $\quad$ dzurotulmutimmah69@gmail.com ${ }^{\left.1^{*}\right)}$ \\ noviprayekti@unibabwi.ac.id $^{2)}$
}

Received 06 March 2021; Received in revised form 16 June 2021; Accepted 09 July 2021

\begin{abstract}
Abstrak
Penelitian ini dimaksudkan untuk membuat model pot tanaman sukulen beralaskan lingkaran dan persegi melalui penggabungan benda geometri bidang dan kurva Bezier Kuadratik yang mencirikan kesimetrian dan terkomposisi dari keratan ellips dan kurva Bezier Kuadratik. Alasan pemilihan bentuk geometri bidang dan kurva Bezier tersebut dimaksudkan agar model pot yang dihasilkan lebih bervariasi dan menarik sehingga dapat meningkatkan nilai jual pot tersebut. Jenis penelitian ini merupakan penelitian terapan (applied research). Dalam penelitian ini, proses pemodelan pot tanaman sukulen dilakukan melalui penggabungan kurva Bezier Kuadratik dan bentuk geometri bidang, khususnya keratan ellips. Adapun prosedur modelisasi pot tanaman sukulen, yaitu pertama, membangun alas dan membagi ketinggian kerangka pot menjadi dua tingkatan dan tiga tingkatan. Kedua, untuk data awal lingkaran, setiap tingkatan akan diisi dengan kurva Bezier Kuadatrik. Sedangkan untuk data awal persegi, akan diisi dengan penggabungan keratan ellips dan kurva Bezier Kuadratik. Ketiga, menginterpolasi kurva Bezier Kuadratik dan keratan ellips. Keempat, menyusun hasil analisis menggunakan software Maple 15 sehingga dihasilkan beberapa pemodelan pot tanaman sukulen berkarakteristik cekung dan campuran.
\end{abstract}

Kata kunci: Ellips; kurva Bezier; lingkaran; persegi; pot.

\begin{abstract}
This research is intended to create a model of a succulent plant pot with a circle and a square base by combining plane geometric shapes and Bezier curves that characterize symmetries and are composed of ellipses and quadratic Bezier curves. The reason for choosing the geometry of the plane and Bezier curves is that the resulting pot model is more varied and interesting so that it can increase the selling value of the pot. This type of research is applied research. In this study, the process of modeling succulent potted plants was carried out by combining Quadratic Bezier curves and plane geometric shapes, especially elliptical cuttings. The procedure for modeling succulent potted plants is as follows. First, build a base and divide the height of the pot model into two and three levels. Second, for the initial data circle, each level will be filled with a Quadratic Bezier curve. As for the initial square data, it will be filled with a concatenation of the ellipse and the Quadratic Bezier curve. Third, interpolate Quadratic Bezier curves and ellipses. Fourth, compiling analysis results by using computer software Maple 15 so that several models of succulent plant pots with concave and mixed characteristics were produced.
\end{abstract}

Keywords: Ellips; bezier Curve; circle; square; pott.

This is an open access article under the Creative Commons Attribution 4.0 International License

\section{PENDAHULUAN}

Succulent adalah istilah yang diberikan bagi sekelompok tanaman dengan karakteristik salah satu atau lebih bagian tubuhnya dapat menyimpan air. Tanaman hias ini cocok untuk menghias ruangan karena mampu bertahan hidup dengan minim cahaya matahari, bentuknya yang unik seperti bunga mekar dan cocok untuk dekorasi apalagi jika dikreasikan dengan terrarium bersama jenis dan warna yang 
beraneka ragam membuat kagum mata memandangnya (Jati, 2016). Selain itu, tanaman succulent juga menjadi pilihan yang tepat karena perawatannya yang mudah, yaitu hanya memerlukan penyiraman seminggu sekali dan tidak memerlukan banyak sinar matahari (Sani \& Lukito, 2020).

Tanaman sukulen dapat ditanam dalam suatu wadah, salah satunya yaitu pot. Pot merupakan media tanam yang terbuat dari tanah liat, semen, atau plastik. Pot memiliki ukuran yang bermacam-macam, untuk pot dengan ukuran relatif besar biasanya diletakkan di luar ruangan atau di halaman rumah. Sedangkan pot dengan ukuran kecil biasanya diletakkan di meja kerja, atau di sudut-sudut tertentu dalam ruangan, sehingga pot dengan ukuran kecil juga berfungsi untuk memperindah ruangan. Pot dengan ukuran kecil biasanya digunakan untuk media tanam dengan jenis tanaman sukulen.

Dari beberapa bentuk pot tanaman sukulen yang telah diperkenalkan terdapat beberapa kelemahan, yaitu pertama, bentuk pot masih terbangun dari satu bentuk geometri ruang (prisma, tabung, dan bola) sehingga pot terlihat monoton dan kurang bervariasi (Gambar 1). Kedua, pewarnaan pada pot hanya terdiri dari satu warna saja, yaitu putih.

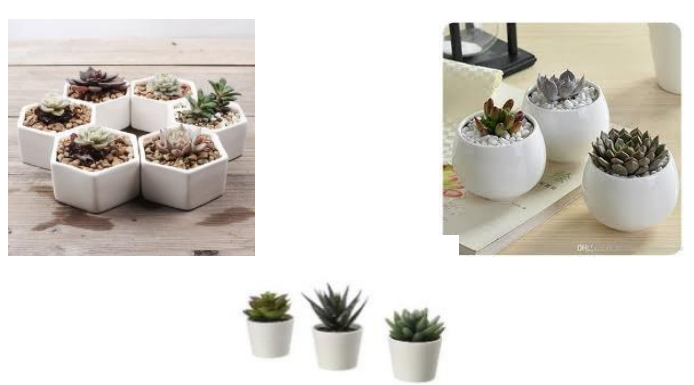

Gambar 1. Beberapa contoh bentuk model pot tanaman sukulen Juhari dan Erny melakukan pemodelan kap lampu duduk melalui penggabungan dan pemilihan parameter pengubah bentuk permukaan Bezier (Juhari \& Octafiatiningsih E., 2015). Emeralda melakukan penelitian tentang modelisasi tugu dengan penggabungan kurva Bezier dan benda geometri ruang, seperti prisma, tabung, dan limas (Emeralda, 2018). Triadi, Juliyanto, dan Ubaidillah juga melakukan pemodelan pada bentuk botol minuman menggunakan kurva Bezier berderajat kurang dari atau sama dengan enam (Triadi et al., 2020). Selain itu, Niaputri, Jannah, Sari, dan Fatmasari melakukan pemodelan menggunakan kurva Bezier terhadap beberapa objek benda, yaitu kerangka jam weker, kursi gantung, rak penataan gelas air minum, serta lampu dinding (Fatmasari, 2019; Jannah, 2017; Niaputri, 2018; Sari, 2019). Selanjutnya, Wahana, Juliyanto, dan Ubaidillah juga melakukan modelisasi handle pintu dengan penggabungan kurva Bezier dan hasil deformasi tabung (Wahana et al., 2020).

Penelitian ini dimaksudkan untuk membuat pemodelan pot tanaman sukulen dengan alas persegi dan lingkaran, melalui penggabungan bentuk geometri bidang dan kurva Bezier yang mencirikan kesimetrian dan terkomposisi dari keratan ellips dan kurva Bezier. Alasan pemilihan bentuk geometri bidang dan kurva Bezier tersebut dimaksudkan agar model pot yang dihasilkan lebih bervariasi dan menarik sehingga dapat meningkatkan nilai jual pot tersebut. Selain itu, pot tanaman dengan bentuk geometris memberi kesan unik, modern, dinamis, dan aplikatif di ruang formal, maupun non formal (Amal et al., 2020).

\section{METODE PENELITIAN}

Jenis penelitian ini merupakan penelitian terapan (applied research). Pada penelitian ini akan dilakukan 
pemodelan pot tanaman sukulen melalui penggabungan bentuk geometri bidang dan kurva Bezier dengan bantuan software Maple 15.

Data yang digunakan dalam penelitian ini adalah data primer. Data primer tersebut berupa dokumentasi atau foto model-model pot tanaman sukulen yang beredar di pasaran. Data atau foto tersebut diambil secara langsung oleh peneliti di sebuah toko tanaman hias "Anna's Florist" yang terletak di Perumahan Mastrip Blok W4, Krajan Timur, Sumbersari, Kec. Sumbersari, Kab. Jember, Jawa timur.

Berdasarkan tinjauan pustaka yang telah dijabarkan, maka proses pemodelan pot tanaman sukulen melalui penggabungan bentuk geometri bidang dan kurva Bezier, yaitu sebagai berikut.

1. Memodelisasi pot berketinggian $t$, dimana $10 \leq t \leq 14 \mathrm{~cm}$, dengan data awal lingkaran berpusat di titik $O(0,0,0)$, berjari-jari $r$, dengan $8 \leq r \leq 10 \mathrm{~cm}$. Dalam hal ini membagi ketinggian pot dan mengisi ketinggian tersebut dengan penggabungan kurva Bezier.

2. Memodelisasi pot berketinggian $t$, dimana $8 \leq t \leq 12 \mathrm{~cm}$, dengan data awal persegi dengan sisi $s$, dengan $6 \leq s \leq 8 \mathrm{~cm}$. Dalam hal ini membagi ketinggian pot dan mengisi ketinggian tersebut dengan keratan ellips dan kurva Bezier.

3. Menyusun hasil analisis 1 dan 2 menggunakan software Maple 15.

Adapun langkah 1-3 sesuai dengan rancangan penelitian seperti Gambar 2.
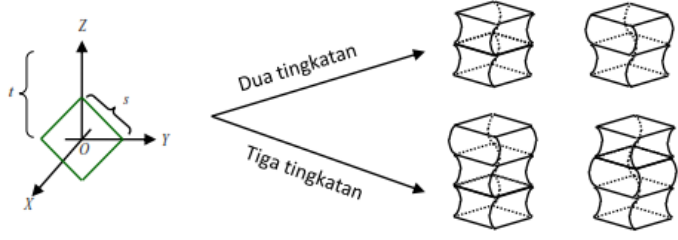

Gambar 2. Alur Penelitian Modelisasi Pot Tanaman Sukulen

\section{HASIL DAN PEMBAHASAN}

Berdasarkan

beberapa permasalahan yang telah dipaparkan, maka konsep dasar dalam penelitian ini, yaitu sebagai berikut.

1. Diberikan data awal lingkaran berpusat di titik $O$, berjari-jari $r$, dan tinggi $t$, dimana $8 \leq r \leq$ $10 \mathrm{~cm}$ dan $10 \leq t \leq 14 \mathrm{~cm}$. Dari data awal tersebut, bagaimana prosedur membangun pot tanaman sukulen yang terkomposisi dari penggabungan kurva Bezier (Gambar 3).

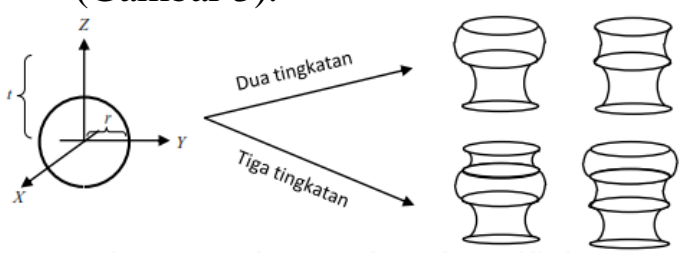

Gambar 3. Rancang bangun pot dengan data awal lingkaran

2. Diberikan data awal persegi pada bidang $X O Y$ dengan sisi $s$ dan tinggi $t$, dimana $6 \leq s \leq 8 \mathrm{~cm}$ dan $8 \leq t \leq 12 \mathrm{~cm}$. Dari data awal tersebut, bagaimana prosedur membangun pot tanaman sukulen yang terkomposisi dari keratan ellips dan kurva Bezier (Gambar 4).

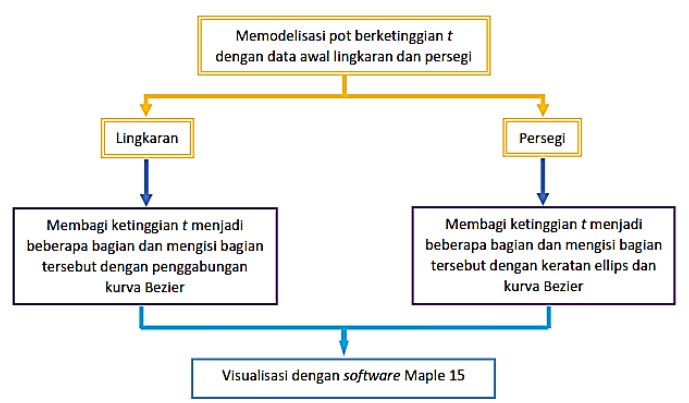

Gambar 4. Rancang bangun pot dengan data awal persegi

Adapun beberapa materi yang digunakan untuk menunjang penelitian ini, yaitu penyajian persegi, lingkaran, ellips, dan kurva Bezier. Misalkan diberikan dua buah titik $A\left(x_{A}, y_{A}\right)$ dan $B\left(x_{B}, y_{B}\right)$ di bidang XOY. Melalui 
kedua data titik tersebut dibangun sebuah persegi $A B C D$ dengan cara, pertama, dibangun segmen garis $\overline{A B}$ dengan formula :

$(1-\lambda)\left\langle x_{1}, y_{1}\right\rangle+\lambda\left\langle x_{2}, y_{2}\right\rangle=\langle x, y\rangle .(1)$ Kemudian dihitung koordinat titik $C$ dan titik $D$ melalui persamaan $\overrightarrow{O C}=$ $\left(\overrightarrow{O B}+k \boldsymbol{n}_{A B}\right)$ dan $\overrightarrow{O D}=\left(\overrightarrow{O A}+k \boldsymbol{n}_{A B}\right)$, dengan $\quad \boldsymbol{n}_{A B}=\frac{\left\langle\left(y_{B}-y_{A}\right),-\left(x_{B}-x_{A}\right)\right\rangle}{\sqrt{\left(x_{B}-x_{A}\right)^{2}+\left(y_{B}-y_{A}\right)^{2}}}$ merupakan normal satuan $\overrightarrow{A B}$ dan $k=$ $|\overline{A B}|$. Selanjutnya membangun segmen garis $\overline{B C}, \overline{C D}$, dan $\overline{A D}$ melalui persamaan (1) sehingga berbentuk persegi $A B C D$ seperti Gambar 5 (Mutimmah \& Rifa'i, 2017).

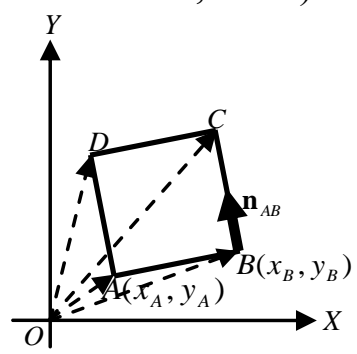

Gambar 5. Penyajian persegi di bidang

Lingkaran adalah himpunan titiktitik di bidang yang berjarak sama dari suatu titik tetap. Titik tetap tersebut dinamakan pusat lingkaran dan jarak yang sama dinamakan jari-jari lingkaran (Khotimah, 2014). Pada bagian ini akan dijelaskan tentang persamaan parametrik lingkaran. Jika $P(x, y)$ sebarang titik pada lingkaran berpusat di $O(0,0),|\overrightarrow{O P}|=r$ dan $\angle P O Q=\theta$, maka bentuk persamaan parametrik lingkaran dapat dicari melalui langkahlangkah berikut (Gambar 6).

$\overrightarrow{O P}=\overrightarrow{O Q}+\overrightarrow{O R}$,

$\langle x-0, y-0\rangle=\langle r \operatorname{Cos} \theta, 0\rangle+$

$\langle 0, r \operatorname{Sin} \theta\rangle$,

$\langle x, y\rangle=\langle r \operatorname{Cos} \theta, r \operatorname{Sin} \theta\rangle$ sehingga

$x(\theta)=r \operatorname{Cos} \theta$,

$y(\theta)=r \operatorname{Sin} \theta$.
Jadi persamaan parametrik lingkaran berjari-jari $r$ berpusat di $O(0,0)$, yaitu:

$\boldsymbol{L}(\theta)=\langle r \operatorname{Cos} \theta, r \operatorname{Sin} \theta\rangle$,

dengan $0 \leq \theta \leq 2 \pi$ dan $r$ adalah suatu konstanta real positif.

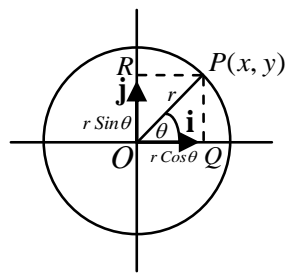

Gambar 6. Penyajian lingkaran

Jika pada persamaan (2) nilai parameter $r$ berharga tidak sama untuk arah $\mathbf{i}$ dan arah $\mathbf{j}$, maka akan diperoleh bentuk elips (Gambar 7). Oleh sebab itu, bentuk persamaan parametrik elips berpusat di $O(0,0)$ yaitu:

$\boldsymbol{E}(\theta)=\langle a \operatorname{Cos} \theta, b \operatorname{Sin} \theta\rangle$,

dengan $0 \leq \theta \leq 2 \pi$, sedangkan $a$ dan $b$ adalah suatu konstanta real positif (Mutimmah, 2014).

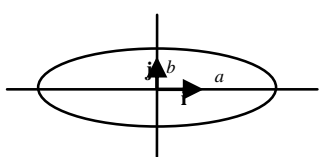

Gambar 7. Penyajian ellips

Kurva Bezier merupakan sebuah kurva parametrik yang sering diterapkan pada komputer grafis dan dalam bidangbidang berhubungan lainnya. Kurva Bezier sangat dikenal karena kemampuannya untuk menghasilkan kurva yang halus (Haryono, 2014). Kurva Bezier berderajat-dua dinyatakan dalam bentuk parametrik yaitu:

$$
\begin{aligned}
V(u)= & K_{0}\left(1-2 u+u^{2}\right)+ \\
& K_{1}\left(2 u-2 u^{2}\right)+K_{2}\left(u^{2}\right)
\end{aligned}
$$

dengan $0 \leq u \leq 1$ (Juhari \& Octafiatiningsih E., 2015). 


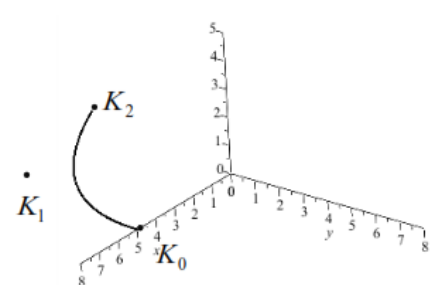

Gambar 8. Kurva Bezier berderajat-dua

\section{Pemodelan Pot Tanaman Sukulen}

\section{A. Model Pot Bertingkat Dua Dengan Data Awal Lingkaran}

Prosedur untuk membangun model pot tanaman sukulen bertingkat dua dengan data awal lingkaran, yaitu sebagai berikut.

1. Membangun alas berupa bidang lingkaran dengan jari-jari $r=8 \mathrm{~cm}$ dan membagi ketinggian menjadi dua tingkatan seperti Gambar 9a.

2. Mengisi tingkatan pertama dengan hasil interpolasi kurva Bezier, dimana titik-titik kontrolnya, yaitu $P_{0}(8,8,0), \quad P_{1}(12,12,10 / 4), \quad$ dan $P_{2}(8,8,5)$ sehingga didapat bangun hasil interpolasi seperti Gambar $9 \mathrm{~b}$.

3. Mengisi tingkatan kedua dengan hasil interpolasi kurva Bezier, dimana titik-titik kontrolnya, yaitu $P_{0}(10,10,7), \quad P_{1}(5,5,7), \quad$ dan $P_{2}(10,10,14)$ sehingga terbangun model pot tanaman sukulen bertingkat dua seperti Gambar 9c.

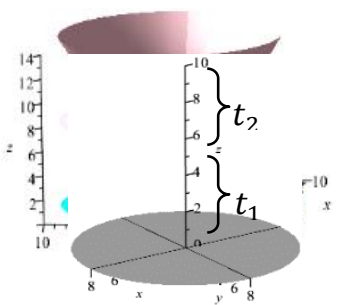

(a)

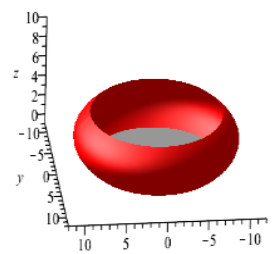

(b)

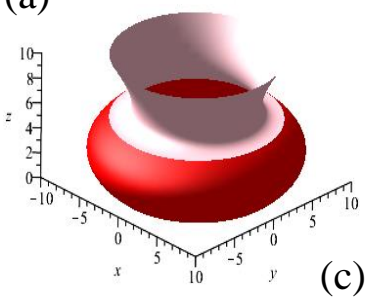

Gambar 9. Modelisasi Pot Tanaman Sukulen Bertingkat Dua Dengan Data Awal Lingkaran

\section{B. Model Pot Bertingkat Tiga Dengan Data Awal Lingkaran}

Prosedur untuk membangun model pot tanaman sukulen bertingkat tiga dengan data awal lingkaran, yaitu sebagai berikut.

1. Mengulang langkah 1-3 pada prosedur membangun model pot tanaman sukulen bertingkat dua dengan data awal lingkaran.

2. Pada tingkatan ketiga akan dibangun hasil dari interpolasi kurva Bezier kuadratik, dimana titik-titik kontrolnya, yaitu $P_{0}(8,8,10), \quad P_{1}(12,12,21), \quad$ dan $P_{2}(8,8,14)$ (Gambar 10).

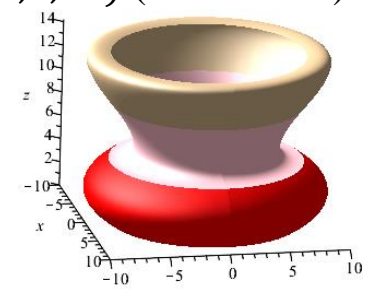

Gambar 10. Modelisăsi Pot Tanaman Sukulen Bertingkat Tiga Dengan Data

Awal Lingkaran

Adapun contoh-contoh modelisasi pot tanaman sukulen dengan data awal lingkaran yang sudah di dapat melalui software Maple, yaitu sebagai berikut (Gambar 11).
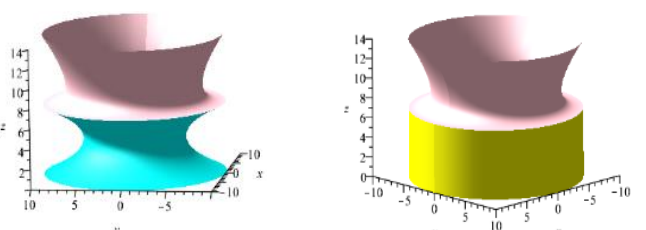

(a) Bertingkat Dua

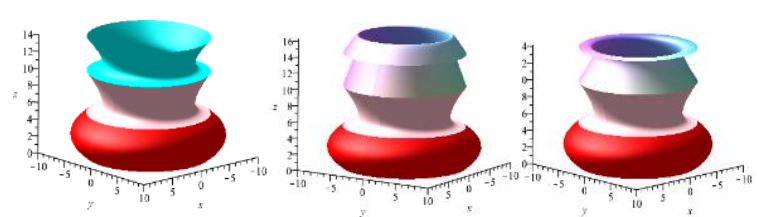

(b) Bertingkat Tiga

Gambar 11. Beberapa Contoh Model Pot Tanaman Sukulen Dengan Data Awal Lingkaran 


\section{Model Pot Bertingkat Dua Dengan Data Awal Persegi \\ Prosedur untuk membangun} model pot tanaman sukulen bertingkat dua, yaitu sebagai berikut.

1. Membangun alas berupa bidang persegi dengan titik-titiknya, yaitu $\quad A(0,6,0), \quad B(6,0,0)$, $C(0,-6,0)$, dan $D(-6,0,0)$ dan membagi ketinggian menjadi dua tingkatan seperti Gambar $12 \mathrm{a}$.

2. Pada tingkatan pertama akan dibangun empat keratan ellips, yaitu masing-masing $1 / 2$ ellips, dengan pusat di titik $(6,0,2)$, $(-6,0,2),(0,6,2)$, dan $(0,-6,2)$ seperti Gambar $12 b$.

3. Menginterpolasi keempat ellips pada tingkatan pertama (Gambar 12c).

4. Pada tingkatan kedua akan dibangun empat kurva Bezier kuadratik (Gambar 12d), dengan titik-titik kontrol kurva Bezier kuadratik pertama yaitu $P_{0}(0,6,3), \quad P_{1}(0,10,3), \quad$ dan $P_{2}(0,6,6)$. Titik-titik kontrol kurva Bezier kuadratik kedua yaitu $P_{0}(0,-6,3), P_{1}(0,-10,3)$, dan $\quad P_{2}(0,-6,6)$. Titik-titik kontrol kurva Bezier kuadratik ketiga yaitu $P_{0}(6,0,3)$, $P_{1}(10,0,3)$, dan $P_{2}(6,0,6)$. Dan titik-titik kontrol kurva Bezier kuadratik keempat yaitu $P_{0}(-6,0,3), \quad P_{1}(-10,0,3)$, dan $P_{2}(-6,0,6)$.

5. Menginterpolasi kurva Bezier kuadratik pada tingkatan kedua (Gambar 12e).

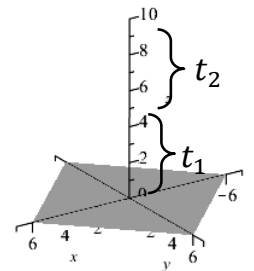

(a)

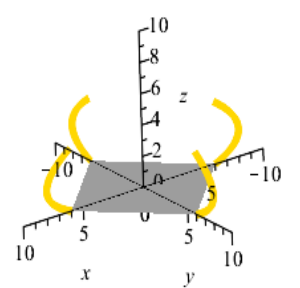

(b)

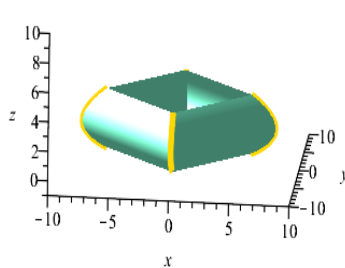

(c)

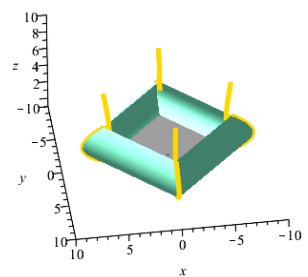

(d)

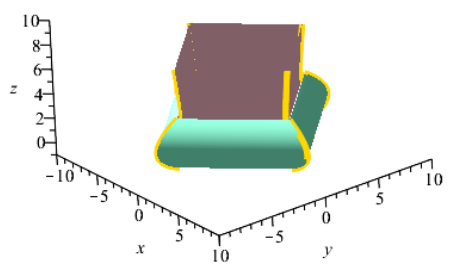

(e)

Gambar 12. Modelisasi Pot Tanaman Sukulen Bertingkat Dua Dengan Data Awal Persegi

\section{Model Pot Bertingkat Tiga Dengan Data Awal Persegi}

Prosedur untuk membangun model pot tanaman sukulen bertingkat tiga dengan data awal persegi, yaitu sebagai berikut.

1. Mengulang langkah 1-5 pada prosedur membangun model pot tanaman sukulen bertingkat dua dengan data awal persegi.

2. Pada tingkatan ketiga akan dibangun empat kurva Bezier kuadratik (Gambar 13a), dengan titik-titik kontrol kurva Bezier kuadratik pertama yaitu $P_{0}(0,8,8)$, $P_{1}(0,4,8)$, dan $P_{2}(0,8,12)$. Titiktitik kontrol kurva Bezier kuadratik kedua yaitu $P_{0}(0,-8,8)$, $P_{1}(0,-4,8)$, dan $P_{2}(0,-8,12)$. Titik-titik kontrol kurva Bezier kuadratik ketiga yaitu $P_{0}(8,0,8)$, $P_{1}(4,0,8)$, dan $P_{2}(8,0,12)$. Dan titik-titik kontrol kurva Bezier kuadratik keempat yaitu $P_{0}(-8,0,8), \quad P_{1}(-4,0,8), \quad$ dan $P_{2}(-8,0,12)$.

3. Menginterpolasi kurva Bezier kuadratik pada tingkatan ketiga (Gambar 13b). 


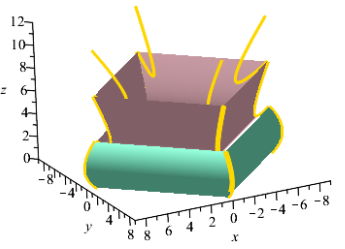

(a)

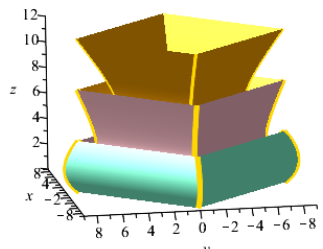

(b)
Gambar 13. Modelisasi Pot Tanaman Sukulen Bertingkat Tiga Dengan Data Awal Persegi

Adapun contoh-contoh modelisasi pot tanaman sukulen dengan data awal persegi yang sudah di dapat melalui software Maple, yaitu sebagai berikut (Gambar 14).
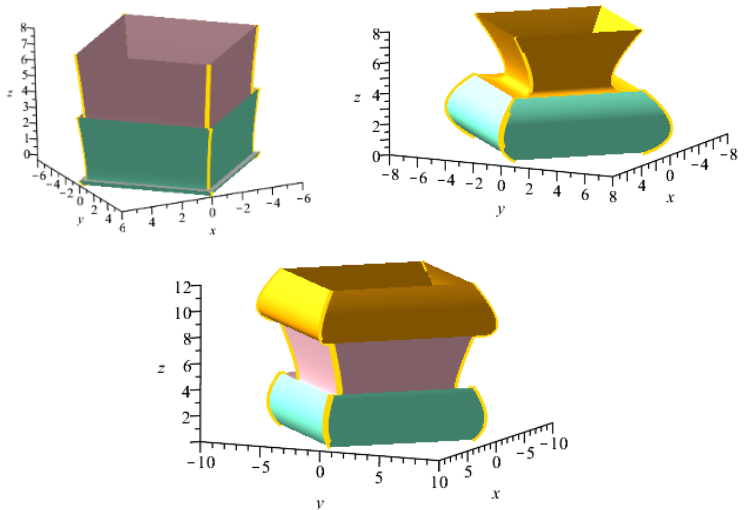

Gambar 14. Beberapa Contoh Model Pot Tanaman Sukulen Bertingkat Dua dan Tiga Dengan Data Awal Persegi

Sehubungan dengan penerapan prosedur pemodelan pot tanaman sukulen menggunakan software Maple, maka dapat dihasilkan beberapa model pot yang lebih bervariasi dan simetris. Hal ini dapat dilihat pada kurva Bezier yang dihasilkan, yaitu membentuk suatu kurva cekung atau cembung. Pada penelitian ini, kurva Bezier Kuadratik cembung dapat dihasilkan melalui pemilihan posisi titik kontrol $P_{1}$ di sebelah kiri titik kontrol $P_{0}$ dan $P_{2}$ untuk sumbu $X$ dan sumbu $Y$ positif, serta pemilihan posisi titik kontrol $P_{1}$ di sebelah kanan titik kontrol $P_{0}$ dan $P_{2}$ untuk sumbu $X$ dan sumbu $Y$ negatif.
Hasil interpolasi dari kurva Bezier Kuadratik cembung juga akan menghasilkan suatu permukaan cembung (Gambar 15).
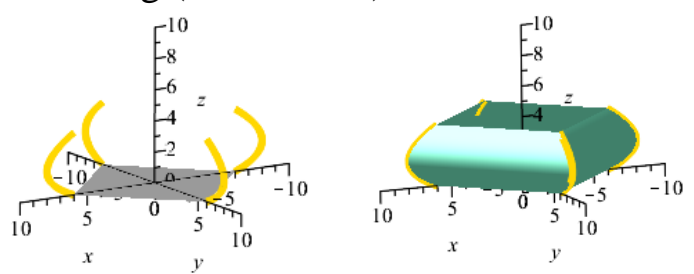

Gambar 15. Kurva Bezier Kuadratik cembung dan hasil interpolasinya

Sedangkan kurva Bezier Kuadratik cekung dapat dihasilkan melalui pemilihan posisi titik kontrol $P_{1}$ di sebelah kanan titik kontrol $P_{0}$ dan $P_{2}$ untuk sumbu $X$ dan sumbu $Y$ positif, serta pemilihan posisi titik kontrol $P_{1}$ di sebelah kiri titik kontrol $P_{0}$ dan $P_{2}$ untuk sumbu $X$ dan sumbu $Y$ negatif. Hasil interpolasi dari kurva Bezier Kuadratik cekung juga akan menghasilkan suatu permukaan cekung (Gambar 16).

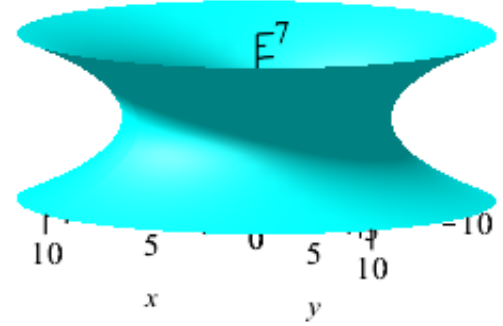

Gambar 16. Hasil interpolasi Kurva

Bezier Kuadratik cekung

Akibat dari permukaan hasil interpolasi kurva Bezier Kuadratik cekung dan cembung, maka dihasilkan beberapa model pot tanaman sukulen dengan karakteristik cekung dan campuran. Pemodelan pot cekung terkomposisi dari permukaan hasil interpolasi kurva Bezier Kuadratik cekung pada setiap tingkatannya (Gambar 17). 


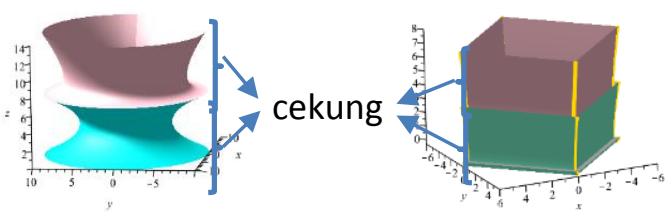

Gambar 17. Model pot tanaman sukulen cekung

Sedangkan pemodelan pot campuran terkomposisi dari permukaan hasil interpolasi kurva Bezier Kuadratik cekung dan cembung pada setiap tingkatannya (Gambar 18).

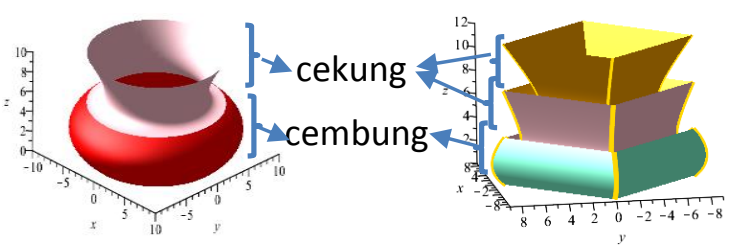

Gambar 18. Model pot tanaman sukulen campuran

Selain itu, beberapa kemudahan
dapat dilihat melalui pemilihan
pembagian ketinggian pot. Pada proses
visualisasi menggunakan software Maple, ketinggian pot dapat dibagi menjadi $n$ tingkatan sesuai dengan kebutuhan. Tetapi dalam penelitian ini, pembagian ketinggian dibatasi hanya untuk dua tingkatan dan tiga tingkatan. Kelebihan lain dalam penelitian ini, yaitu dapat mengurangi biaya dalam proses trial and error pada saat proses produksi pot di pabrik karena proses trial and error di lakukan pada saat proses visualisasi menggunakan software Maple.

\section{KESIMPULAN DAN SARAN}

Berdasarkan hasil penelitian yang telah dilakukan, maka dapat dihasilkan beberapa model pot tanaman sukulen cekung dan campuran. Adapun prosedur pemodelan pot tanaman sukulen dengan data awal lingkaran dan persegi, yaitu sebagai berikut. Pertama, membangun alas dan membagi ketinggian modelisasi pot menjadi dua dan tiga tingkatan. Kedua, untuk data awal lingkaran, setiap tingkatan akan diisi dengan kurva Bezier Kuadatrik, sedangkan untuk data awal persegi, akan diisi dengan penggabungan keratan ellips dan kurva Bezier Kuadratik. Ketiga, menginterpolasi kurva Bezier Kuadratik dan keratan ellips.

Saran untuk penelitian selanjutnya, yaitu dapat melakukan pemodelan pot tanaman hias lainnya, baik indoor atau outdoor, menggunakan kurva Bezier Kubik atau dengan penggabungan benda geometri bidang dan geometri ruang lainnya.

\section{DAFTAR PUSTAKA}

Amal, C. A., Amalia, A. A., Andayaningsih, S., \& Diterima, N. (2020). POTOMETRIUM (Pot Tanaman Geometris dan Terarium) serta Pemasaran Digital Bagi Kelompok Penjual Tanaman Hias di Kelurahan Maccini Sombala, Kota Makassar POTOMETRIUM (Geometric and Terraium Pot Plants) and Digital Marketing for The Ornamental Plant Traders . Jurnal Panrita Abdi, 4(1), 110118.

http://journal.unhas.ac.id/index.php /panritaabdi

Emeralda, M. H. (2018). Modelisasi Tugu dengan Penggabungan Benda Dasar Geometri dan Kurva Bezier [Universitas Jember]. In Jember: Jurusan Matematika Fakultas MIPA.

Fatmasari, C. (2019). Modelisasi Lampu Dinding Melalui Penggabungan Hasil Deformasi Benda-benda Geometri dan Kurva Bezier [Universitas Jember]. In 
DOI: https://doi.org/10.24127/ajpm.v10i2.3605

\section{Jember: Jurusan Matematika Fakultas MIPA.}

Haryono, A. (2014). Studi Pembentukan Huruf Font Dengan Kurva Bezier. Jurnal Teknika, 3(1), 69-78. https://doi.org/10.34148/teknika.v3 i1.22

Jannah, R. E. S. (2017). Modelisasi Kursi Gantung dengan Penggabungan Hasil Deformasi Benda Geometri Ruang dan Kurva Bezier [Universitas Jember]. In Jember: Jurusan Matematika Fakultas MIPA.

Jati, N. S. W. (2016). Perancangan Buku Ilustrasi Berkreasi dengan Tanaman Hias Sukulen untuk Lanjut Usia [Institut Seni Indonesia]. In Yogyakarta: Program Studi S-1 Desain Komunikasi Visual Jurusan Desain Fakultas Seni Rupa. http://digilib.isi.ac.id/1487/

Juhari, \& Octafiatiningsih E. (2015). Penerapan Kurva Bezier Karakter Simetrik dan Putar Pada Model Kap Lampu Duduk Menggunakan Maple. CAUCHY: Jurnal Matematika Murni Dan Aplikasi, 4(1), 28-34.

Khotimah, H. (2014). Desain Tempat Perhiasan dengan Kerangka Prisma Segitiga Samasisi [Universitas Jember]. In Jember: Jurusan Matematika Fakultas MIPA.

Mutimmah, D. (2014). Modelisasi Lampion Dengan Penggabungan Kerangka Bangun Geometri Ruang Dan Lipatan Bidang [Universitas Jember]. In Jember: Jurusan Matematika Fakultas MIPA.

Mutimmah, D., \& Rifa'i, P. B. (2017). Pemodelan Motif Keramik Dengan Teknik Penggabungan BangunBangun Geometri Datar Dengan Konsep Transformasi. AKSIOMA: Jurnal Program Studi Pendidikan
Matematika, 6(3), 407-413. https://doi.org/10.24127/ajpm.v6i3. 1156

Niaputri, D. A. (2018). Modelisasi Kerangka Jam Weker dengan Penggabungan Benda Geometri dan Kurva Bezier [Universitas Jember]. In Jember: Jurusan Matematika Fakultas MIPA. https://repository.unej.ac.id/bitstrea m/handle/123456789/90496/Dinar Aven Niaputri141810101010.pdf? sequence $=1 \&$ is Allowed=y

Sani, N., \& Lukito, W. (2020). Perancangan Strategi Desain Untuk Meningkatkan Brand Awareness Succulent Bandung. EProceeding of Art \& Design, 7(2), 2527-2534.

Sari, H. A. (2019). Konstruksi Rak Penataan Gelas Air Minum Menggunakan Hasil Deformasi Benda-benda Geometri dan Kurva Bezier [Universitas Jember]. In Jember: Jurusan Matematika Fakultas MIPA.

Triadi, M. B. F., Juliyanto, B., \& Ubaidillah, F. (2020). Aplikasi Kurva Bezier Pada Desain Botol Minuman. Jurnal MIMS, 20(1), 18.

Wahana, N. P., Juliyanto, B., \& Ubaidillah, F. (2020). MODELISASI HANDLE PINTU dengan Penggabungan Kurva Bezier dan Hasil Deformasi Tabung. Jurnal MIMS, 20(2), 6576. 